\title{
Certolizumab pegol has a different profile from other anti-TNFs, including golimumab, in a variety of in vitro assays
}

\author{
G Fossati, A Nesbitt ${ }^{*}$ \\ From 5th European Workshop on Immune-Mediated Inflammatory Diseases \\ Sitges-Barcelona, Spain. 1-3 December 2010
}

\section{Introduction}

Differences in structure and in vitro properties of antiTNF agents may account for different modes of action and clinical outcomes. The activities of certolizumab pegol (CZP), etanercept (ETA), infliximab (IFX) and adalimumab (ADA) have been compared using in vitro assays [1]. However, golimumab (GLM) has not previously been evaluated.

\section{Aim}

To compare the activity of CZP with other anti-TNFs, including GLM, in a range of in vitro assays.

\section{Methods}

Neutralisation of human TNF was assessed in the L929 bioassay. The activity of anti-TNFs at inhibiting LPSdriven IL- $1 \beta$ secretion by monocytes was measured by ELISA. To determine apoptosis induction, activated peripheral blood lymphocytes and monocytes were examined by Annexin V staining using flow cytometry. The effect on neutrophil necrosis was measured by myeloperoxidase release. An isotype-matched control was used in all assays except the L929 bioassay.

\section{Results}

The $\mathrm{IC}_{90}$ neutralisation activity in the $\mathrm{L} 929$ bioassay was $0.3 \mathrm{ng} / \mathrm{mL}$ for ETA, $4 \mathrm{ng} / \mathrm{mL}$ for GLM, $15 \mathrm{ng} / \mathrm{mL}$ for $\mathrm{ADA}$, and $20 \mathrm{ng} / \mathrm{mL}$ for IFX, versus $2.5 \mathrm{ng} / \mathrm{mL}$ for CZP. CZP was the most potent inhibitor of LPS-driven IL-1 $\beta$ secretion $\left(\mathrm{IC}_{50} \sim 0.1 \mathrm{ng} / \mathrm{mL}\right)$, followed by GLM (20 ng/mL).
GLM, ADA, IFX and ETA induced apoptosis of monocytes and lymphocytes to a similar degree.

CZP caused no increase in apoptosis above isotypematched control levels. In the neutrophil necrosis assay, ADA, IFX and GLM caused $\sim 70 \%$ necrosis at $100 \mu \mathrm{g} / \mathrm{mL}$, and ETA $48 \%$. CZP did not increase the level of necrosis above the level of the control.

\section{Conclusion}

The ability of GLM, IFX, and ADA to neutralise human TNF was inferior to CZP and ETA. CZP had a different profile to the other anti-TNFs; it was the most potent at inhibiting monocyte LPS-driven IL- $1 \beta$ production, did not induce apoptosis of activated monocytes and lymphocytes, and did not cause neutrophil necrosis. The clinical relevance of these in vitro effects is unknown. Nevertheless, these assays show interesting differences between anti-TNFs.

Published: 25 November 2010

\section{Reference}

1. Nesbitt A, Fossati G, Bergin M, Stephens P, Stephens S, Foulkes R, Brown D, Robinson M, Bourne T: Mechanism of action of certolizumab pegol (CDP870): In vitro comparison with other anti-tumor necrosis factor alpha agents. Inflamm Bowel Dis 2007, 13:1323-1332.

doi:10.1186/1479-5876-8-S1-P37

Cite this article as: Fossati and Nesbitt: Certolizumab pegol has a

different profile from other anti-TNFs, including golimumab, in a variety of in vitro assays. Journal of Translational Medicine 2010 8(Suppl 1):P37. 